\title{
Strategic orientation in evaluation of supply chain activities
}

\author{
Javad Sofiyabadi $^{a^{*}}$, Mohmmad mahdi movahedi ${ }^{a}$ and Sakineh Noori Nasab ${ }^{b}$
}

${ }^{a}$ Department of Management, Firoozkooh Branch, Islamic Azad University, Firoozkooh, Iran

${ }^{b}$ Department of industrial management, Semnan Branch, Islamic Azad University, Semnan, Iran

\begin{tabular}{l}
\hline A R T I C L E I N F O \\
\hline Article history: \\
Received October 18, 2011 \\
Received in Revised form \\
February, 2, 2012 \\
Accepted 8 April 2012 \\
Available online \\
April 112012 \\
\hline Keywords: \\
SCM \\
Effective factor within function of \\
Supply Chain \\
BSC \\
DEMATEL
\end{tabular}

DEMATEL

\begin{abstract}
A B S T R A C T
Employment of supply chain management could impact the entire functional and practical aspects of industry and services positively and change the manager's attitude toward the implementation of supply chain management systems from a cost-oriented attitude to an enabling attitude towards better activities with other chain members. Yet still many organizations do not have the required vision within the identification of strategic appropriate measure in implementation, evaluation and usage of proper benchmarks to attain an integrated chain. Constantly supply chain management activity can be introduced as a tied up with strategic level of organization. Hence, it is a necessary with an overall strategic approach to identify the criteria, which enable us to include the whole process level of chain, financial matter of chain activities, visible and invisible properties, human activity and turn all these activities into an integrated approach to resolve supply chain difficulties. In this paper, we present an integrated balanced score card combined with DEMATEL technique to prioritize different alternatives for supply chain implementation.
\end{abstract}

(C) 2012 Growing Science Ltd. All rights reserved.

\section{Introduction}

For many years, many corporations had to improve the details of their market strategies by concentrating on customer retention. They participated in distribution network management of entire prior companies, which provided the inputs either directly or indirectly and indeed distribution network of post companies, which provided the delivery and post-sell services. Therefore, the companies along with expansion and complication of these activities developed their own operational approach from an interior company's core into a chain of activities with other companies and by this means, the concept of supply chain and its management emerged in the management literature as supply chain management (SCM). The rapid change of SCM in recent years and the expansion of new technology application in processes have changed the chain activities, which swiftly and suitably react toward the chain strategic challenges by posing the sensitivity in chain strategic atmosphere.

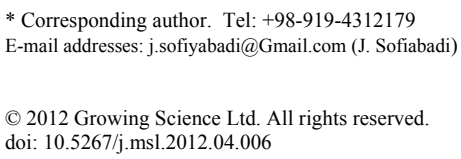


Many chain partners maximize their overall added value through actively participating in SCM (Barber, 2008). Supply chain activities must be managed properly in an appropriate and integrated manner based on designed, planned and organized frameworks. This managerial approach is considered as a complicated and structured model required for producing goods and presenting services in an utmost efficient and effective manner (Quiett, 2002). An efficient supply chain needs to achieve its own ends using long-term strategic alliance, supplier-buyer collaboration, logistic management of entire chain, joint planning, inventory control and information sharing. Waste and inventory reduction, reworking reduction via cut back in costs and enhancement of quality (Chan et al., 2006), performance improvement in presenting services to the clients via increment of product accessibility and decline in order the cycle time can be regarded and introduced as the consequences of companies partnership in supply chain activities. Attaining to an improved outcome within frequent time periods along with the chain require the actual performance of chain to be measured. Through information feedback, motivation increments, communications and diagnosis of problems, grounds of acceptance simplification and integration of supply chain members are provided. An effective evaluation system provides a benchmark for system comprehension and impacts the entire behaviors through the system and also makes available suitable information upon the gained results out of supply chain member's endeavor and foreign stakeholders (Stefanović \& Stefanović, 2011).

Therefore, appropriate and punctual performance assessment is highly important in general system components and chain individual system. With regard to the investigation of supply chain management literature, lack of an appropriate performance measurement system as a major barrier in supply chain effective management introduced and put into the discussion. Koplic and Shefi (1995) believed that managers constantly measure the SCM and make sure that these measures reflect an ongoing evolution chain. They also noted that, conventionally evaluation of SCM more tended to measure expense, time and preciseness. Indeed, Goskeron et al. (2004) in evaluation of chain activities in addition to abovementioned, introduced other factors like order lead-time, delivery operation, customer query time, cash flow time in 3 strategic, tactical and operational levels. However, Biemen (1999) believed that a traditional approach in measurement of chain performance is not sufficient and explained that these approaches depended mostly on the criteria of expenses as the initial measure. In investigation of supply chain literature between 1995 -2004 Goskeren and Cobo (2007) identified nearly 90 criteria of supply chain where $38 \%$ was related to financial criteria and $60 \%$ was related to functional criteria (Shaw et al., 2010).

Probably different approaches can be used for supply chain activities performance measurement but with regard to abovementioned and considering the strategic atmosphere of supply chain, it can be expressed that the balanced scorecard is one of the most fitful performance measurement systems in chain strategic level. Balanced score card (BSC) pushes the traditional boundaries of supply chain performance measurement and investigates the financial and none-financial aspects of that with an overall systematic perspective (Brewer \& Speh, 2000; Lapiede, 2000). In this way, many of researchers did their own SCM performance measurement researching activities based on BSC where each one could manage with different attitudes investigated and précised about some agents. There are many investigations introduced into perspective and discussion but the recent researches are focused on the implementation of BSC in SCM evaluation. Bhagwat and Sharma (2007) investigated the small and medium enterprise in India using BSM technique in SCM daily operations. They explained that the mentioned that their proposed model provides a more balanced approach for manager's effective evaluation. Varma et al. (2008) evaluated oil supply chain performance via a combination of analytic hierarchy process (AHP) and BSC. They determined agents' supply chain performance based on 4 perspective of BSC using experts' feedbacks. The importance of these 4 perspectives with regard to oil supply chain performance respectively downward include: customer, financial, internal process, innovation and learning. Chia et al. (2009) investigated senior managers of receiving services companies and senior managers of logistic service provider on supply chain management activities and stated that companies have to focus on traditional financial measures such 
as national income, profit before tax and expense cut. However, the study indicated that invisible criteria play important role on customer satisfaction and in other index of logistic performance some agents such as on-time delivery and customer satisfaction were introduced.

Anbanadam et al. (2009) presented an approach for producers and retailers' collaboration measurement range. They investigated some variables such as superior management commitment, information sharing, trust among supply chain partners, long term relationship, danger and reward sharing and they measured collaboration levels by the help of Graph theory. Thakkar et al. (2009) integrated some outstanding features of BSC and SCM operation reference to present an overall companies performance measurement index model in small and medium size. They also introduced a set of performance indicators for supply chain process such as resource, structure and delivery in small and medium companies. These indicators explained criteria in different stages of supply chain such as purchase, production and customer orders. They also presented a model to evaluate supply chain and planning in small and medium companies stated an overall instruction about execution and evaluation (Thakkar et al., 2009). Bigliardi and Bottani (2010) did a survey based on Delphi method on two food industries using financial and non-financial indicators by the means of BSC. Their investigation results revealed that the investigated companies are identical in three perspective of $\mathrm{BSC}$ and on the other hand there were some different results about perspective of learning and growth.

Jalalinaini et al. (2011) suggested a performance evaluation system by the means of integrated approach of evolution game theory and BSC in green supply chain management. Singh (2011) devised a framework via interpretation structural modeling (ISM) to improve supply chain coordination where 32 agents were considered and they were classified in 6 groups including top management commitment, mutual understanding, organizational agents, information flow, relations, decision making and responding. The results showed that, top management commitment and strong mutual understanding were main factors in coordination improvement among the whole factors. Based on the explained investigations, we realize that we must pay special attention for evaluation and supply chain activities.

In this paper, we present an empirical study for the implementation of BSC and DEMATEL technique to find important criteria associated with SCM. The organization of this paper first presents the literature review in section 2 and details of our implementation are given in section 3 . The paper ends with concluding remarks.

\section{Literature review}

\subsection{Supply chain management}

Intensive competitions in global market, short-term life products, customer expectation elevation have created motivation among business agencies to investment more on own supply chains. This matter along with constant communication technology progress and transportation bring about motivations for supply chain constant renovation and its managerial approaches. Supply chain includes supplier, production centers, warehouses, distribution centers, retail market, work in process raw materials and completed products that are running among different welfares (Simchietal, 2007). Indeed, supply chain includes a network of contributors and different operational channels from inside and outside, which are affected upon favorability of supply chain components. The primary objective of supply chain is customer satisfaction. In a way that the concerning product with the highest quality and the minimum price and by the concerning time to be delivered to customers. In order to optimize the inside chain supply chain process each member must be coordinated with other members. Fig. 1 displays supply chain process in a schematic manner. 


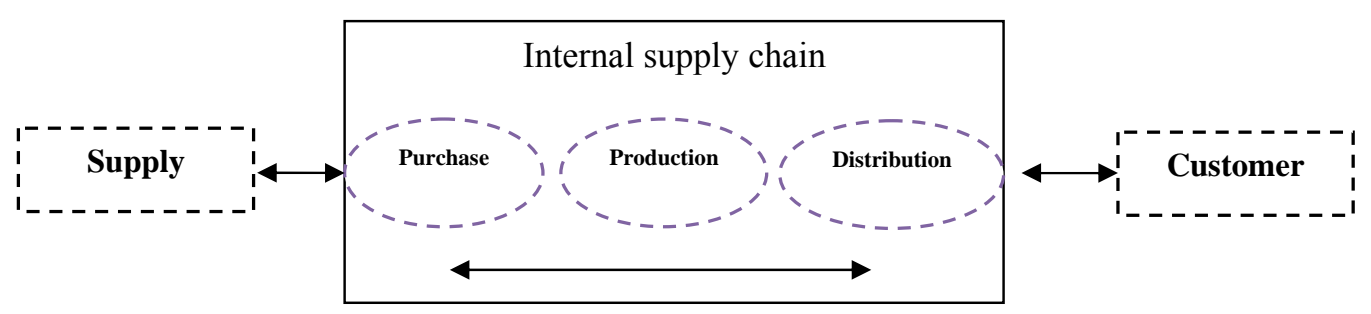

Fig. 1. Supply Chain Process

In general, supply chain consists of two or more organizations, which are formally separated from each other and are attached to each other by the flow of materials, information and financial flows. These organizations can be agencies that present primary materials, spars and parts, completed product or services like warehousing, wholesaling, retail selling and even the ultimate customer is included too. For an effective supply chain management it is essential that supplier and customers in a coordinated manner and with partnership provide perfect information relationship and continuous interaction with each other. This matter means fast flow of information through the chain principles, which enable them to create a very effectual supply chain. The concept of SCM in early decade of 1980 was introduced and then the academic knowledge in this subject was developed. Supply chain management defines as a set of managerial approaches and coordination of activities transferred from raw material supplier to ultimate customers. In addition, it is regarded as a responsive reaction towards environmental pressure by organizations. SCM is a long term orientation, discipline or inside-company integration, which includes either combining or mediating collaborative relationship (Kotzab et al., 2011). Generally, there are varieties of definitions for SCM. SCM concept is derived from the concept of purchasing and supply management and logistics and transportation management. Lee et al. (2006) stated that SCM synonyms with integration based on supply originated from traditional purchasing and material performance. However, in terms of logistics and transportation management, SCM synonyms with integration of logistics and concentration on declining the on-hand supply both inside and in entire organization's SCM (Chong et al., 2011). Despite the fact that there is not a unique definition on SCM there are many similarities among the variety of presented definitions, which is the existence of the constant coordination and concentration on integration with other parties in supply chain to present value to the ultimate customers. SCM is considered more than a new business approach and because of that it can be introduced as a strategic change in organizational dominant culture and principles and by which the foreign partners set some optimal activities in their organizational agenda to reach a joint objective (Meehan \& Muir, 2008).

\subsection{Supply Chain Performance Measurement}

Generally, performance assessment is defined as an effectiveness process and activity's efficiency. Effectiveness is a domain, which meets the customer's needs while efficiency measures the quality of economic usage of organization's resources (Neely et al., 1995). A practical means of supply chain performance assessment must be able to consider both efficiency and effectiveness. Supply performance assessment can be divided into two measures of qualitative and quantitative methods. Business incorporations and universities most often use the quantitative method. This method suffers from 2 major problems: One is associated with the amount of time required for data collection the other is how to reach reliable information for data assessment (Foggin et al., 2004). There are literally different methods for measuring the relative performance of various suppliers (CSCNP, 2004). Sinha and Bobo (1998), offered a supply chain simulation model, which works by the explanation of supply chain dynamics, devised depot service index. Quick scan audit methodology is a strong method originally presented for individual supply chain healthiness. This approach creates a set of integrated and organized practical characteristics, which can evaluate far more effective details of rival value chains sample distribution (Naim et al., 2002; Bannomyoung et al., 2005). Charan et al. (2008) used 
interpretational structured modeling for categorizing supply chain's enabling variables. This model evaluated the supply chain performance in strategic level and simplified the top manager's awareness toward supply chain variables. But this model cannot evaluate supply chain in tactical and operational level. Chan and Qi (2003) offered a new approach for supply chain management by the help of systematic thinking approach and a processed based model. They explained that a company must develop a team of cross functional for performance evaluation team. Information are collected precisely on supply chain activities by the performance evaluation team and then they are analyzed by fuzzy model. However, in this method much more information are collected but due to the complexity of this approach, people are not much willing to use this technique. Criticisms affiliated with current means of performance evaluation include: data collection restriction, inaccessibility of required information, complicated analyzes, implementation problem and time \& resources restriction. Shepherd and Gunter (2006) presented the shortage of current performance evaluation methods from his attitude with very precise investigation. The method concentrates more on cost items and other items such as customers and rivals are neglected (DeToni \& Tonchia, 2001). There are many performance evaluation means created based on cost oriented function and quantitative means concentrate upon value or none-costing function. There is a shortage on balanced approach between financial and none- financial function (Gunasekaran, 2001). Financial and none- financial indicators show different dimensions of supply chain. Therefore, presenting both indicators are required. There are some limitations on the theory, indeed, literature on this subject is quite limited. There is not a crystal clear contrast among indicators in 3 strategic, tactical and operational level and most of available means' measurement level is not clear. Finally, there is no overall systematic thought once developing supply chain performance dimensions.

\section{Research Methodology}

\subsection{Balanced Score Card}

Kaplan and Norton (1992) introduced the idea of balanced score card (BSC). They expressed that this approach evaluates organizations from 4 perspective including financial perspective, customer, internal process, growth and learning to achieve their strategic goals. Therefore, for this reason this approach is considered to be as a supportive means for strategic management (Kaplan \& Norton, 1992). By this way, Kaplan and Norton expressed that for a complete evaluation of organization's performance we must look at the firm in 4 perspectives where these fourfold perspectives are displayed in Table 1 (Kaplan \& Norton, 2001).

\section{Table 1}

\begin{tabular}{cl}
\hline perspective of balanced score card & \\
\hline Customer's perspective (added value vision) & $\begin{array}{l}\text { Mission: achieving to desired vision via value presentation to } \\
\text { customers }\end{array}$ \\
$\begin{array}{c}\text { Financial perspective (stockholder vision) } \\
\text { Internal perspective (processed oriented vision) }\end{array}$ & $\begin{array}{l}\text { Mission: Financial success via value presentation to stock holder } \\
\text { processes }\end{array}$ \\
Growth \& learning perspective (future vision) & $\begin{array}{l}\text { Mission: achieving to desired vision via innovation enhancement } \\
\text { and change ability through continues improvement }\end{array}$ \\
\hline
\end{tabular}

The recent research has concentrated on effectiveness of BSC approach usage in strategic management. Kaplan and Norton (1996) proposed a method by the help of strategy map offered via converting a fourfold model into a complicated framework, which attains through combination of strategy and vision. They extended their idea by the help of cause \& effect relationship among fourpart balanced score card presented. The previous performance evaluation common approaches mainly concentrated on financial dimensions of organization and focused its indicators on but the fourfold perspective of BSC could create a balance between long-term objectives and short-term ones, financial and none- financial relationships, internal and external organization's atmosphere 
(Meng \& Minogue, 2011). The success in these fourfold structures depends on the fact that each single perspectives comply with the organization's strategy. However, the only ambiguity point about the balanced scorecard is on integration and amalgamation of these indicators in four sections of cause \& effect chain that there are through entire four perspectives. In general, the basic platform of BSC can be investigated in that the measure of growth and learning can be a major driver for measure of business internal process and measure of internal process regarded as a driver to customer vision measure and finally measure of customer can be a driver to financial measure (Papalexandris et al., 2004). The BSC provides a unified framework, and one language for relationship between strategy and vision ( Hanafizadeh \& Moayer, 2008).

\subsection{DEMATEL decision making technique}

The Battelle Geneva Institute can be introduced as the origin of DEMATEL decision making technique development (Gabus \& Fontela, 1972,1973). This approach used for analyzing sophisticated problems in the world and totally was based on quality dimensions of problems' evaluation. Basically, DEMATEL was used in unarranged, incompatible and opposite phenomena to reach some integrated solutions for those troubles. In recent years this approach has been highly regarded in Japan because this method specifically presents an approach fitting for complicated structural imagination and well displays the cause \& effect relationship between benchmarks (Chiu et al., 2006). This technique well and truly depicts the contextual relationships among one problem's elements. DEMATEL is able to converts the relationship between cause \& effect into structural system model (Ya \& Hsiao, 2008).

This technique can be investigated in 9 steps. Step 1: recognizing the on hand \& available elements, Step2: determining explicit relationships, Step3: combination of expert group vote and diagraph drawing, Step4: determining intensity of ultimate relationship, Step5: system relationship intensity matrix, Step6: formation of relative intensity dominant matrix on relationship, Step7: formation of relative intensity matrix of direct and indirect relationship, Step8: formation of relative intensity matrix of indirect relationshipStep9: determining hierarchy of impress.

\section{Results}

\subsection{Supply chain management \& BSC}

One of networking economical pattern is supply chain management where a set of approaches in management and coordination of entire chain from the supplying management of supplier to customers of customer are involved (Grown \& Tallon, 2003). Supply chain management like every other systems and managerial solution need performance evaluation system to successfully identify and determe how much the customer's needs are met, assisting the organization to understand the process ,exploring unknowns which organization were not aware of and finally the carried-out planning improvement ( Morgan, 2007). But as of yet there has not been sufficient attention specified to supply chain performance measurements (Bhagwat \& Sharma, 2009). Cai et al. (2009) expressed that performance evaluation systems do not necessarily have a balanced approach, strategic alignment and systematic thought and performance measures can be roughly identified. To overcome this difficulty, BSC for supply chain performance evaluation can be used. The BSC can help the superior managers make the organization's vision and strategies operational and aid concentrate on crucial drivers (Cai et al., 2009). Supply chain evaluations by the help of BSC are performed through four attitudes including: internal perspective-process and mission, foreign partner perspective like supplier and distribution channels, financial perspective and customer perspective. BSC does an overall performance evaluation for supply chain management (Kalkar \& Sachin, 2010). This approach via presenting a new concept of strategic map tries to state and determine the cause \& effect relationships among the strategic objectives (Calvamora et al., 2005). The cause and effect 
relationship among criteria could provide a fitting pattern in implementation of supply chain performance evaluation system. According to the wide investigations into the executed research, the criteria on Table 2 can be used with emphases on supply chain strategic activities dimensions (Sharma \& Bhagwat, 2007; Barber et al., 2008; Hervani et al., 2005; Kaplan \& Norton, 1996; Varma et al., 2006; Bigliardoni \& Bottani, 2010)

\section{Table 2}

Evaluation criteria of supply chain activities with emphasis on their identification via BSC

\begin{tabular}{cl}
\hline \multirow{2}{*}{ Financial } & $\begin{array}{l}\text { Length of supply chain, Market share, investigation, Operational cost, Spending cost, Fines and } \\
\text { penalties, Revenue recycling, Value added per employee, Profitability chain activities, Net profit , } \\
\text { productivity ratio, Return on investment, variations against budget, Delivery performance, Suppliers } \\
\text { cost saving initiatives }\end{array}$ \\
\hline & $\begin{array}{l}\text { Safety Products, Rate of return customers, Delivery on time, Customer satisfaction, Distribution lead } \\
\text { time, Reliability of delivery, Customer query time, level of customer perceived value of product, range } \\
\text { of products and services, buyer-supplier partnership level, delivery lead time, responsiveness to urgent } \\
\text { deliveries, effectiveness of distribution planning schedule, quality of delivery documentation, driver } \\
\text { reliability for performance, quality of delivered goods }\end{array}$ \\
\hline \multirow{2}{*}{$\begin{array}{l}\text { Internal } \\
\text { process }\end{array}$} & $\begin{array}{l}\text { Integration with supply chain partners, rework, supplier rejection rate, Total cash flow time, supplier } \\
\text { lead time against industry norms, accuracy of forecasting techniques, Product development cycle time, } \\
\text { Purchase Order cycle time, Planned process cycle time, effectiveness of master production schedule, } \\
\text { total inventory cost as: incoming stock level, work-in-progress, scrap value and finished goods in } \\
\text { transit, efficiency of purchase order cycle time }\end{array}$ \\
\hline $\begin{array}{l}\text { Learning } \\
\text { \& growth }\end{array}$ & $\begin{array}{l}\text { Training needs, Appraisals on time employee, supplier assistance in solving technical problems, } \\
\text { supplier ability to respond to quality problems, buyer-supplier collaboration, supplier's booking in } \\
\text { procedures, order entry methods, flexibility of service systems to meet particular customer needs }\end{array}$ \\
\hline
\end{tabular}

\subsection{Supply chain evaluation criteria priority identification}

In this section, we present details of ranking for the implementation of DEMATEL for four BSC perspectives. Table 3 shows details of prioritization according to financial criteria, Table 4 expresses details of our implementation on customers' perspectives, Table 5 is associated with internal process and finally Table 6 demonstrates details of the ranking based on learning and growth factors.

\section{Table 3}

Identify priority financial criteria in the evaluation of supply chain activities

\begin{tabular}{lccccc}
\hline Item & $\mathrm{R}+\mathrm{J}$ & $\mathrm{R}-\mathrm{J}$ & Permeability & setting penetration & Final ranking \\
\hline Length of supply chain & 5.69 & 0.56 & 2.57 & 3.12 & 2 \\
Market share & 5.13 & -0.98 & 3.05 & 2.07 & 7 \\
Investigation & 4.86 & -0.09 & 2.48 & 2.39 & 5 \\
Operational cost & 4.31 & 0.94 & 1.68 & 2.62 & 4 \\
Spending cost & 3.67 & -0.41 & 2.04 & 1.63 & 10 \\
Fines and penalties & 3.01 & -0.10 & 1.56 & 1.46 & 12 \\
Revenue recycling & 3.64 & 0.07 & 1.78 & 1.85 & 8 \\
Value added per employee & 5.37 & 1.52 & 1.92 & 3.44 & 1 \\
Profitability chain activities & 5.89 & -0.45 & 3.17 & 2.72 & 3 \\
Net profit vs. productivity ratio & 4.36 & -0.89 & 2.63 & 1.74 & 9 \\
Return on investment & 5.57 & 0.67 & 2.45 & 3.12 & 2 \\
variations against budget & 3.03 & -0.62 & 1.83 & 1.21 & 13 \\
Delivery performance & 4.98 & -0.67 & 2.82 & 2.16 & 6 \\
Suppliers cost saving initiatives & 2.59 & 0.45 & 1.07 & 1.52 & 11 \\
\hline
\end{tabular}




\section{Table 4}

Identify priority customer criteria in the evaluation of supply chain activities

\begin{tabular}{lccccc}
\hline & $\mathrm{R}+\mathrm{J}$ & $\mathrm{R}-\mathrm{J}$ & Permeability & setting penetration & Final ranking \\
\hline Safety Products & 5.33 & -0.54 & 2.93 & 2.4 & 15 \\
\hline Rate of return customers & 7.33 & -1.13 & 4.23 & 3.1 & 11 \\
\hline Delivery on time & 7.39 & 0.58 & 3.41 & 3.98 & 6 \\
\hline Customer satisfaction & 7.9 & -0.12 & 4.01 & 3.89 & 8 \\
\hline Distribution lead time & 7.01 & 0 & 3.5 & 3.51 & 10 \\
\hline Reliability of delivery & 7.25 & -1.53 & 4.39 & 2.86 & 12 \\
\hline Customer query time & 5.52 & -0.28 & 2.9 & 2.62 & 13 \\
\hline Level of customer perceived value of product & 5.5 & -0.25 & 3.01 & 2.49 & 14 \\
\hline Range of products and services & 6.41 & 2.49 & 1.96 & 4.45 & 2 \\
\hline Buyer-supplier partnership level & 9.41 & -0.38 & 4.89 & 4.51 & \\
\hline Delivery lead time & 7.93 & -0.07 & 4 & 3.93 & 1 \\
\hline Responsiveness to urgent deliveries & 9.02 & -0.21 & 4.61 & 4.41 & 7 \\
\hline Effectiveness of distribution planning schedule & 7.82 & 0.62 & 3.6 & 4.22 & 3 \\
\hline
\end{tabular}

\section{Table 5}

Identify priority internal process criteria in the evaluation of supply chain activities

\begin{tabular}{lccccc}
\hline Item & $\mathrm{R}+\mathrm{J}$ & $\mathrm{R}-\mathrm{J}$ & Permeability & setting penetration & Final ranking \\
\hline Integration with supply chain partners & 8.18 & -0.8 & 4.49 & 3.69 & 5 \\
Rework & 5.39 & 1 & 2.19 & 3.2 & 10 \\
Supplier rejection rate & 5.72 & 1.36 & 2.18 & 3.54 & 7 \\
Total cash flow time & 9.08 & -1.3 & 5.19 & 3.89 & 3 \\
Supplier lead time against industry norms & 6.19 & -1.1 & 3.65 & 2.55 & 12 \\
Accuracy of forecasting techniques & 4.93 & 3 & 0.96 & 3.97 & 2 \\
Product development cycle time & 6.56 & -0.34 & 3.45 & 3.11 & 3.7 \\
Purchase Order cycle time & 9.11 & -1.71 & 5.41 & 3.39 & 4 \\
Planned process cycle time & 6.92 & -0.14 & 3.53 & 4.42 & 8 \\
Effectiveness of master production schedule & 8.48 & 0.35 & 4.06 & & 1 \\
Total inventory cost as: incoming stock level, & & & & & \\
Work-in-progress, scrap value and finished & & & & 3.62 & 6 \\
goods in transit & 7.91 & -0.67 & 4.29 & 3.27 & 9 \\
Efficiency of purchase order cycle time & 6.19 & 0.34 & 2.93 & & \\
\hline
\end{tabular}

\section{Table 6}

Identify priority learning \& growth criteria in the evaluation of supply chain activities

\begin{tabular}{lccccc}
\hline Item & R+J & R-J & Permeability & penetration & Rank \\
\hline Training needs & 4.42 & 2.88 & 0.77 & 3.65 & 2 \\
\hline Appraisals on time employee & 4.15 & -0.68 & 2.41 & 1.73 & 8 \\
\hline Supplier assistance in solving technical problems. & 5.57 & $1.04-$ & 3.3 & 2.27 & 7 \\
\hline supplier ability to respond to quality problems & 7.31 & -1.24 & 4.28 & 3.03 & 4 \\
\hline Buyer-supplier collaboration & 7.37 & 0.08 & 3.65 & 3.72 & 1 \\
\hline Supplier's booking in procedures & 4.32 & 1.01 & 1.66 & 2.67 & 5 \\
\hline Order entry methods & 4.68 & 0.3 & 2.19 & 2.49 & 6 \\
\hline Flexibility of service systems to meet particular customer needs & 7.54 & -1.30 & 4.42 & 3.12 & 3
\end{tabular}

In summary, we have determined the priorities of SCM implementation based on four different perspectives. In terms of financial perspectives, value added per employee is the most important item, followed by return on investment and profitability chain activities. In terms of customer perspectives, buyer-supplier partnership level is ranked first followed by range of products and services and responsiveness to urgent deliveries. In terms of internal process, effectiveness of master production schedule is the first priority, followed by accuracy of forecasting techniques and total cash flow time. In terms of learning and growth, buyer-supplier collaboration is the most important criteria, followed by the required training and flexibility of service systems to meet particular customer needs.

\section{Conclusion}

In this paper, we have presented a hybrid of BSC and DEMATEL technique to prioritize important factors in implementation of SCM. The proposed model considered different factors associated with 
four various perspectives of financial, internal process, customer and learning and growth. The implementation of DEMATEL yielded the priorities of different factors. In terms of financial perspectives, value added per employee is the most important item, followed by return on investment and profitability chain activities. In terms of customer perspectives, buyer-supplier partnership level is ranked first followed by range of products and services and responsiveness to urgent deliveries. In terms of internal process, effectiveness of master production schedule is the first priority, followed by accuracy of forecasting techniques and total cash flow time. In terms of learning and growth, buyersupplier collaboration is the most important criteria, followed by the required training and flexibility of service systems to meet particular customer needs.

\section{References}

Simchi-Levi, D. (2007). (MIT), Philip Kaminsky (University of California, Berkeley) and Edith Simchi-Levi (ILOG), McGraw-Hill, 2003-2007, ISBN: 0-07-284553-8

Anbanadam, R., Banwat, D.K., \& Shankar, R. (2009). Evaluation of supply chain collaboration: a case of apparel retail industry in India. International Journal of Productivity and performance measurement, 60(2), 82-98.

Barber, E. (2008). How to measure the value in value chains. International Journal of Physical Distribution \& Logistics Management, 38(9), 685-698.

Brewer, P.C \& Speh, T.W. (2000). Using The Balanced Scorecard to measure supply chain performance. Journal of Business logistics, 21(1),75-94.

Bhagwat, R. \& Sharma, M. K. (2007). Performance measurement of supply chain management: A balanced scorecard approach, Computers \& Industrial Engineering 53, PP. 43-62.

Bigliardi, B., \& Bottani, E. (2010). Performance measurement in the food supply chain: a balanced scorecard approach. Facilities, 28(5/6), 249-260.

Benomyong, R., Basnet, C., Childerhouse, P., Deakins, E., Disney, S.M., Naim, M.M., Towill, D.R. (2005). Internationalizing the quick scan audit methodology, 18th international conference on production research proceeding. Salerno, Italy, July 31-August 4, 2005.

Bhagwat, R. \& Sharma, M.K. (2009). An application of the integrated AHP-PGP model for performance measurement of supply chain management. Production Planning \& Control, 20(8), 678-690.

Calvo-Mora, Arturo; Leal, Antonio; Jose Roldan. (2005). Relationship between the EFQM model criteria: a study in Spanish university, Total quality management, Vol. 16, No. 6, PP. 741-770.

Chong, A.Y.L, Chan, F.T.S, Ooi, K.B., \& Sim, J.J. (2011). Can Malaysian firms improve organizational/innovation performance via SCM? Industrial Management \& Data Systems, 111(3), 410-431.

Chan, F., Chan, H., Lau, H., \& Ip., R. (2006). An AHP approach in benchmarking logistics performance of the postal industry. Benchmarking: An International Journal, 13(6), 636-661.

Chia, A., Goh, M., Hu, S.H. (2009). Performance measurement in supply chain entities: balanced scorecard perspective. Benchmarking: An International Journal, 16(5), 605-620.

Charan, P., Shankar, R., \& Baisya, R. (2008). Analysis of interactions among the variables of supply chain performance measurement system implementation. Business Process Management Journal, 14(4), 512-529.

Chan, F., \& Qi, H. (2003). Feasibility of performance measurement system for supply chain: a process-based approach and measures. Integrated Manufacturing Systems, 14(3), 179-190.

Cai, J., Liu, X., Xiao, Z., Liu, J. (2009). Improving supply chain performance management: A systematic approach to analyzing iterative KPI accomplishment. Decision Support Systems, 46, 512-521.

CSCMP. (2004). Supply Chain Management Process Standards. Council of supply chain management professionals, Oak Brook, IL.

Chiu, Y.J., Chen, H.C., Shyu, J.Z., \& Tzeng, G.H. (2006). Marketing strategy based on customer behavior for the LCD-TV. International Journal of Management and Decision Making, 7(2-3), 143-165.

De Toni, A., \& Tonchia, S. (2001). Performance measurement systems: models, Characteristics and measures. International Journal of Operations \& Production Management, 21(1/2), 46-70.

Foggin, J., Mentzer, J., \& Monroe, C. (2004). A supply chain diagnostic tool. International Journal of Physical Distribution \& Logistics Management, 34(10), 827-855.

Grown, C. R., \& Tallon, W. J. (2003). Enhancing supply chain practices through human resource management. Journal of Management Development, 22(10), 32-44.

Gunasekaran, A, Patel, C, \& Tirtiroglu, E. (2001). Performance measures and metrics in supply chain environment. International Journal of Operations \& Production Management, 21(1/2),71-87.

Gabus, A., \& Fontela, E. (1972). World problems: An invitation to further thought within the framework of DEMATEL. Battelle Geneva Research Centre, Geneva. 
Gabus, A., \& Fontela, E. (1973). Perceptions of the world Problematique: Communication Procedure. Communicating with those Bearing Collective Responsibility (DEMATEL No. 1), Battelle Geneva Research Centre, Geneva.

Hervani, A.M., Helms, M., \& Sarkis, J. (2005). Performance measurement for green supply chain management. Benchmarking: An International Journal, 12(4), 330-353.

Hanafizadeh, P., \& Moayer, S. (2008). A methodology to define strategic processes in organizations. Business Process Management, 14(2), 219-227.

Chen, H.C., Yu, Y.W. (2008). Using a strategic approach to analysis the location selection for high-tech firms in Taiwan. Management Research News, 31(4), 228-244.

Jalali Naini, S. G., Aliahmadi, A., Jafari-Eshandari, M. (2011). Designing a mixed performance measurement system for environmental supply chain management using evolutionary game theory and balanced scorecard: A case study of an auto industry supply chain. Conservation and Recycling, 55, 593-603.

Kotzab, H., Teller, C., Grant, D. B., \& Sparks, L. (2011). Antecedents for the adoption and execution of supply chain management. Supply Chain Management: An International Journal, 16(4), 231-245.

Kaplan, R.S., \& Norton, D.P. (1992). The balanced scorecard-measures that drive performance. Harvard Business Review, 70(1), 71-79.

Kalkar, P.C., \& Borgave, S. (2010). Benchmarking supply chain with balanced scorecard: A conceptual framework. Journal of Business Excellence, 1(2), 01-05.

Knotts, T.L, Jones, S.C, \& Udell, G.G. (2006). Insights from research using a balanced approach to measure merchandising supplier performance. Measuring Business Excellence, 10(1), 4-13.

Kaplan, R.S \& Norton, D.P. (1996). Using the balanced scorecard as a strategic management system. Harvard Business Review, 74(1), 75-85.

Kaplan, R. S., \& Norton, D. P. (2001). The strategy-Focused Organization: How Balanced scorecard companies Thrive in New Business Environment. Harvard Business School Press, Boston, MA.

Lapiede, L. (2000). True measures of supply chain performance. Supply Chain Management Review, 4(2), 25-28.

Meehan, J. \& Muir, L. (2008). SCM in Merseyside SMEs: benefits and barriers, The TQM Journal, Vol. 20, No. 3, PP. 223-232.

Meng, X., \& Minogue, M. (2011). Performance measurement models in facility management: a comparative study. Facilities, 29, 1-24

Morgan, C. (2007). Supply network performance measurement: future challenges?, The International Journal of Logistics Management, 18(2), 255-273.

Neely, A, Gregory, M, \& Platts, K. (1995). Performance measurement systems design: a literature review and research agenda. International Journal of Operations \& Production Management, 15(4), 80-116.

Naim, M., Childerhouse, P., Disney, S., Towill, D. (2002). A supply chain diagnostic methodology: determining the vector of change. Computers and industrial Engineering, 43(1/2), 135-157.

Papalexandris, A., Ioannou, G., \& Prastacos, G. (2004). Implementing the balanced scorecard in Greece: a software firm's experience. Long Range Planning, 37(4), 292-293.

Quiett, W.F. (2002). Embracing supply chain management. Supply Chain Management Review, 40-47.

Sharma, M. K., \& Bhagwat, R. (2007). An integrated Bsc-AHP approach for supply chain management evaluation. Measuring Business Excellence, 11(3), 57-68.

Stefanović, N., \& Stefanović, D. (2011). Supply chain performance measurement system based on scorecard and web portals. COMSIS, 8(1), 167-192.

Shepherd, C., \& Günter, H. (2006). Measurement supply chain performance: current research and future directions. International Journal of Productivity and Performance management, 55(314), 242-258.

Sinha, R.K., \& Bubu, A.S. (1998). Quality of customer service in supply chain system: a diagnostic study. International Journal of Quality \& Reliability Management, 15(8/9), 844-859.

Singh, R.K. (2011). Developing the framework for coordination in supply chain of SMEs. Business Process Management Journal, 1(4), 619-638.

Shaw, S., Grant, D. B., \& Mangan, J. (2010). Developing environmental supply chain performance measures. Benchmarking: An International Journal, 17(3), 320-339.

Thakkar, J., Kanda, A., Deshmukh, S.G. (2009). Supply chain performance measurement framework for small and medium scale enterprises. Benchmarking: An International Journal, 16(5), 702-723.

Varma, S., Wadhwa, S., \& Deshmukh, S.G. (2006). Measuring productivity in the supply chain: use of the balanced scorecard. Productivity, 46(2-3), 330-338.

Varma, S., Wadhwa, S., \& Deshmukh, S.G. (2008). Evaluating Petroleum supply chain performance, Application of analytical hierarchy process to balanced scorecard. Asia Pacific Journal of Marketing and Logistics, 20(3), 343356. 